\title{
The Model of the Sociocultural Educational Environment of the Classical University
}

\author{
Anna Patlina \\ Department of Social Work, Psychology and Pedagogy of \\ Higher Education \\ Kuban State University \\ Krasnodar, Russia \\ E-mail: anna-2029@yandex.ru
}

Ovsep Gomtsyan

Department of Social Work, Psychology and Pedagogy of Higher Education

Kuban State University

Krasnodar, Russia

E-mail: ovsep86@mail.ru

\author{
Elena Shlyubul \\ Department of Social Work, Psychology and Pedagogy of \\ Higher Education \\ Kuban State University \\ Krasnodar, Russia \\ E-mail: yelyena.shl@yandex.ru
}

Svetlana Lyausheva

The Office of Graduate School and Dissertation Councils Adyghe State University

Maykop, Russia

E-mail: slyausheva@list.ru

\begin{abstract}
The article deals with the results of a pilot research of the analysis of the socio-cultural educational environment of the Kuban State University, Krasnodar. The authors pay attention to the problems of students' expectations from the university, describe Soft skills, forms and methods of their development through building the model of the sociocultural educational environment of a classical university.
\end{abstract}

Keywords-sociocultural educational environment; model; soft skills; scientific potential; competencies

\section{INTRODUCTION}

There are many precedents for organizing communities or models that supervise youth scientific activities at a university (Plekhanov Russian University of Economics, Lomonosov Moscow State University, Moscow City Pedagogical University, Tomsk State University, Tomsk State Pedagogical University) in Russia. The analysis of existing models allows us to talk about the presence of scientific potential of youth scientific activities, realized in improving the quality of youth scientific activity and expanding the range of subjects of interaction. As a rule, such models are precedential in nature and their effectiveness is deferred so it is difficult to draw conclusions about their productivity and the need for special forms of managerial support for development and scaling.

The solution of the problem of improving the quality of specialists training and the formation of competencies issues during the training period was worked out by: Shmeleva N.B., Khutorskoy A.V., A.V. Baidenko, Zimnyaya I.A., Boyarsky E.A., Kolomiyets S.M., Kiazimov K.G., Kanov V.I., Bordovsky G.A., Prozumentova G.N., Burykhin B.S., Grigoryev S.I., Slastenin V.A., Veselovskaya N.S., Ilyazova M.D., Zeer E.
The organization of education is always a communication as a person is not a subject of education but a community is Meaning does not live in a person but in a community arising in the process of communication between people. To realize the anthropological context, a person must become a subject of a joint activity, a communication subject, a community subject. In addition, in this sense we are moving to the humanitarian context, because communities, consistency, communications, these are not anthropological issues but a humanitarian education organization ones. By humanitarian organization of education, we understand the creation of an open educational space, where each of its subjects has its own semantic content creating a single environment.

Bearing its cultural heritage a university acts as a separate part of a sociocultural field, acting as an institution as a subject of joint activity. It is important to emphasize the social levels of interaction of all participants in joint activities when considering them. Because of the very position taken in social structures and processes, common tasks set as a result of such activities are solved and that cultural heritage created in the process of joint activity is carried. Considering the educational process and educational space as a part of a common sociocultural field by which we understand the external social and cultural environment in a combination of a small and large social circle with its cultural focus and heritage that surrounds a subject, in our case, we mean a person, consisting of the resources and capabilities of both human and material technical support, which, in addition to traditional financing for such activities, also includes information resources.

A university is, first of all, a special sociocultural environment within the framework of which the formation or development of the social and activity space of a human subject and their competencies occurs, in our case these are 
soft competencies - soft skills. The authors point out that it is the environment in which a subject is immersed that allows the person manifest oneself and to be a full-fledged participant in joint activities, forming their own subjective position, finding their own place of "presence" in the open educational space [1]. Speaking about the open educational space in socio-cultural environment of the University, we are talking about the accessibility and possibilities of each subject of the open educational space to use this environment through system network communications, solving the tasks set, thereby accumulating and improving knowledge and socio-cultural capital.

\section{DESCRIPTION OF PRECEDENT}

The following domestic authors give exhaustive ideas about the problems of education as a phenomenon of social life: V.A. Shapovalov, V.G. Navodnov, V.N. Shubkin, V.T. Lisovsky, O.N. Chetverikova, V. YA. Nechaev, G.M. Motova, D.L. Konstantinovsky, L.N. Kogan, L. Ya. Rubina, M.N. Rutkevich, M.Kh. Titma, O.V. Dolzhenko, S.S. Belikova, S.S. Sheveleva, M.N. Filatova, D.S. Erofeev, E.A. Burdukovskaya, F.R. Filippov, E.A. Saar. It is necessary to mention the following foreign authors: A. Bloom, B. Simon,K. Manheim, N. Chomsky, R. Merton, F. Mahlup, E. Durkheim. It is also important to mention some contemporary authors whose works are devoted to the study of precisely the problems of the quality of education: A.A. Ostapenko, V.G. Navodnov, V.I. Slobodchikov, V.P. Bederkhanova, T.A. Hagurov, E.A. Sukhanova, S.A. Stepanov, G.E. Zborovsky, G.M. Motova, N.E. Pokrovsky, N. SH. Nikitina, P.E. Scheglov, E.A. Shuklina and others. According to V.I. Slobodchikov, A.A. Ostapenko, the current situation in domestic education can be characterized as a systematic crisis. Thus, in their opinion, today there is a lack of a clear image of the future of the country, "fuzziness" and discrepancy of the educational ideal of a graduate, the dodging between so-called pedagogical technologies. As a result, there is an infinite change in the content and standards of education and teaching every 3-4 years, as well as the randomness of its means that is called variability. According to O.N. Chetverikova, today the scientific and educational system of our country is exposed to a severe pressure from the transnational innovative business, the aim of which is to create a platform for introducing the latest global management technologies based on our educational system.

For a more detailed study of the problems of the university space and identifying the processes of formation and development of sociocultural educational space in Kuban State university, a study was conducted that reveals teachers' opinion on the university sociocultural educational environment and reveals students' expectations of the learning process at the university. In 2014, a sociological study was conducted by the university. 75 university teachers, which are members of the Association of Classical Universities of Russia, were interviewed. 42,66 \% are men, 57,34 are women. According to the respondent's age the sample was as follows: $25-35$ years old $-36,0 \%$; 36-45 years old $-24,0 \%, 46-55$ years old $-28,0 \%$; 56-65 years old $-12,0 \% .18,66 \%$ of respondents have a doctoral degree, $52 \%$ have a candidate of science degree, and $29,33 \%$ have no degree.

"Fig. 1" shows evaluative judgements about the state of modern education in general and the state of education of classical universities in particular. Evaluative judgements were made regarding the quality of the classical university and the quality of the entrants' admission system. The highest percentage on responses is presented.

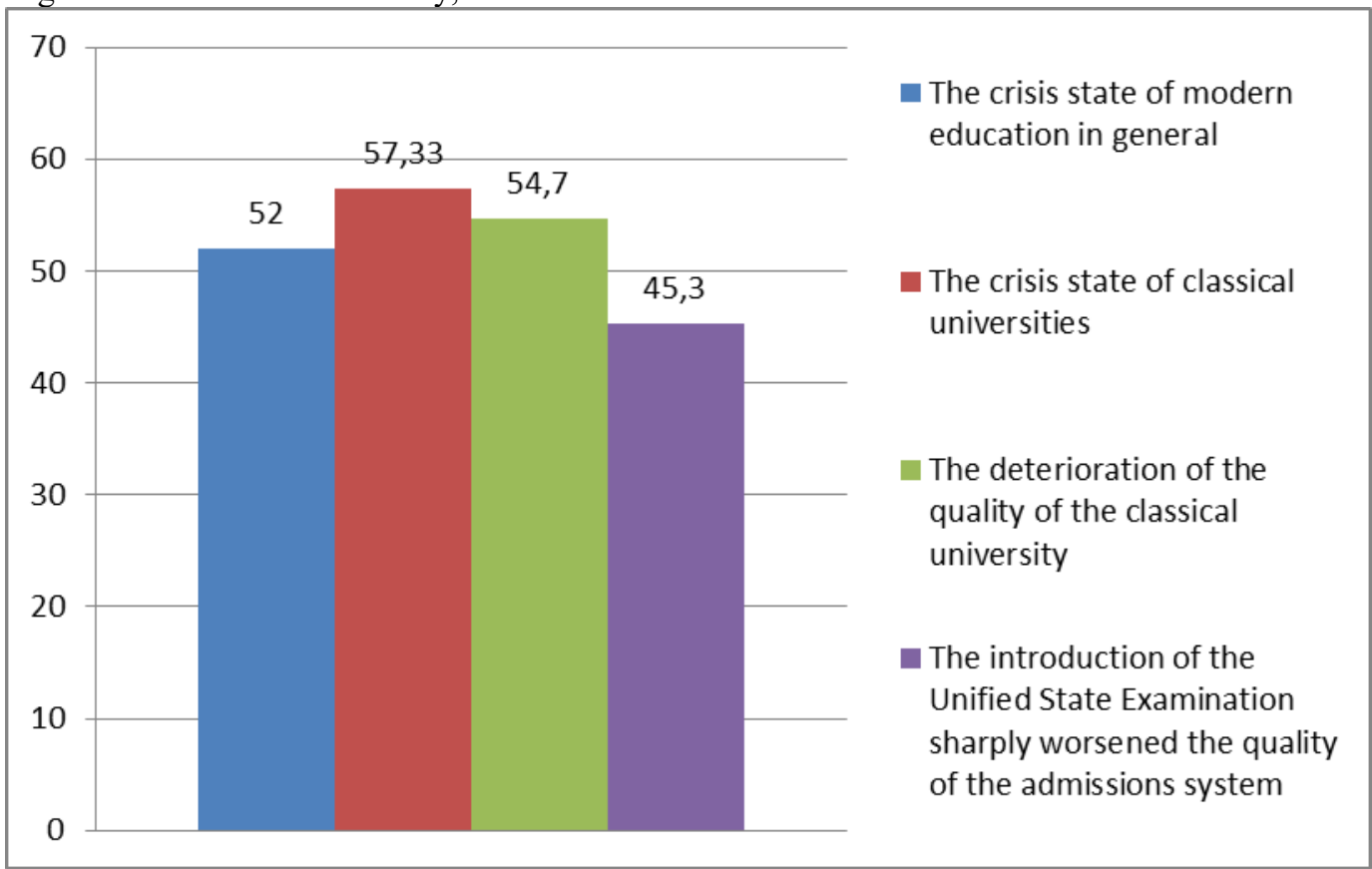

Fig. 1. The faculty of the university showed the signs of a classical university. 
"Fig. 2" represents the maximum values.

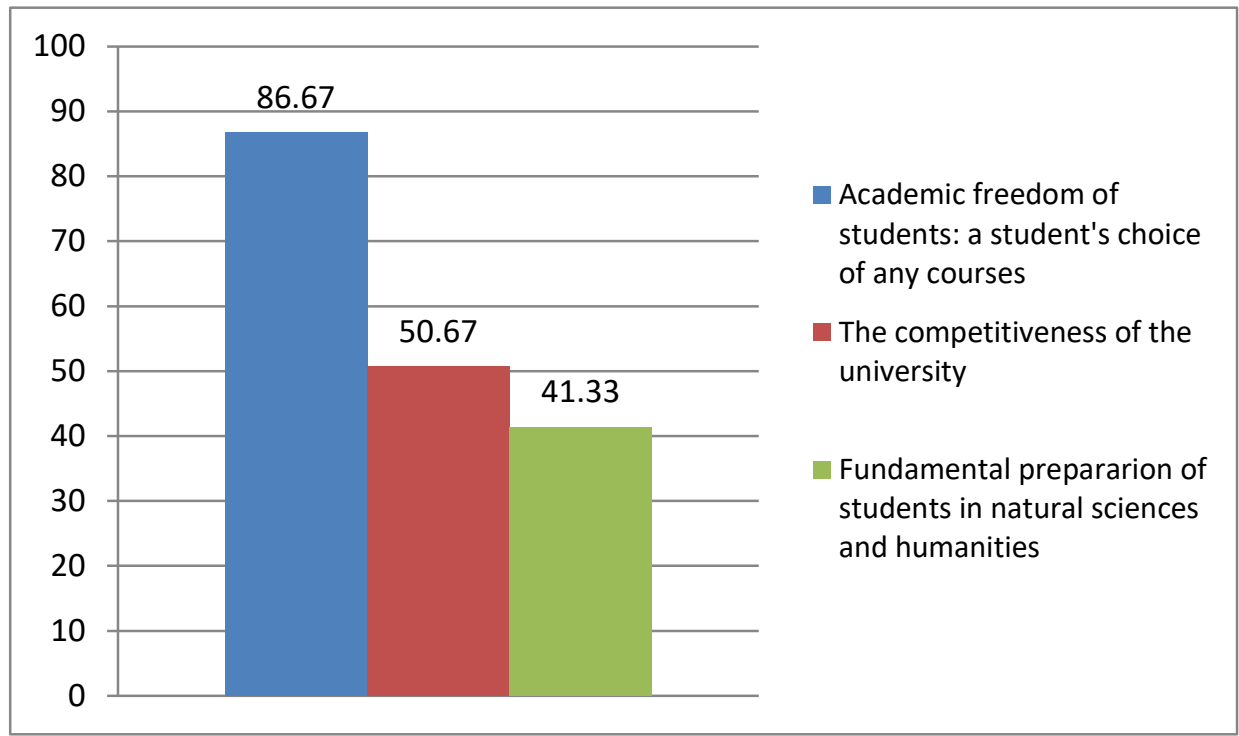

Fig. 2. The maximum values.

"Fig. 2" shows us the judgments of the faculty regarding the main factors in the Russian science development. The highest percentage on responses is presented.

The most general views of the faculty can be expressed in a few words: "to revoke the reforms", "to return the old system", "to increase salary", "to increase the budget on science", "to give the teacher to students so you will get quality!", "it is impossible to work due to constant reports and paperwork". These opinions are exaggerated, of course, but almost everyone will agree with them. Any educational system at any time was rigid to innovations and reforms and teachers and scientists have been always dissatisfied with salaries and funding.

By means of pilot sampling among students, the sophomores from "Social work" department were chosen. The focused group interview was the method of this study. This study was also conducted in 2014 at the Department of Management and Psychology at Kuban State University. 24 students participated in it, whose age was 19-20 years old. $84 \%$ are girls, $16 \%$ are young men. The focus group was held during two days 11.5 hours each. Both on the first and second day 12 students took part in the study.

A modern student sees the getting of a diploma as their main goal of going to a university, which was the response of most respondents:

- to continue education and assert yourself in life;

- my parents wanted so;

- to find what I am interested in ;

- to gain knowledge to go up the "ladder of life";

- not to let yourself degrade;

- it is accepted so.
The answers received point out the external motivation of entrants that they do not know who they want to be. A modern applicant goes to a university because that is how the system "school-university" works: you graduate from school, pass the state exams and either go or not to a university. And the answer "to get a diploma" indicates the lack of formation of the image of a future profession.

We asked a qualifying question "What are the motives for your higher education?" Such formulation let us reveal the career component of the education received, namely:

- you cannot get a god job without it;

- a part of the subjects is interesting in itself without practical application;

- for appearances' sake when applying for a job;

- I'm pleased to understand that I will soon have a higher education;

- self-improving and self-actualization.

Thus, a logical chain is observed in the answers: the goal is a diploma, the motive is a good job. Another important motive among students is self-actualization, which is a social motive.

The question "What is the value of education for you?". On the contrary, education for students is of a personal value:

- I study to learn something new for myself;

- to get a diploma, learn something new, self-actualize;

- you can't get a job without it; there will be an opportunity to maintain the conversation with smart people;

- to gain new knowledge, self-development; 
Thus, speaking about students' expectations from the

- to find meaning and interest in life;

"Under what conditions will you be interested in education?" The answers are the following:

- if the material is taught skillfully;

- if a teacher treats students with understanding;

- if the material is interesting and it will be explained to me in an understandable form;

- if I listen to things which interest and excite me;

- if there is a good teacher, an interesting subject and an interesting form of teaching.

"What teacher's personal qualities are important to you?". The students answered: "responsibility", "understanding", "responsiveness", "humor", "kindness", "affability", "empathy".

"What qualities do the best teachers have or should have?":

- a bright, able to get interested in, experienced, kind, good speaker;

- humor, intelligence, knowledge, versatility, equity;

- humor, to be able to make students interested;

- the ability to combine theory with their own practice and give interesting examples;

- the ability to establish contact with students.

And to the last question "What did you expect from the university itself?" the following answers were received:

- providing students with a good accommodation (dormitory);

- the possibility of staying in the reading room $24 / 7$ as well as the availability of computers with Internet access there;

- high scholarships;

- providing an opportunity of more frequent attending of open lectures of prominent people, scientists, not only domestic but foreign ones;

- it would be preferable to have open lectures with the best scientists of KubSU as often as possible at the faculty;

- $24 / 7$ sport center at the territory of the campus;

- the existence of different hobby groups at the university;

- it would be preferable for university to help its graduates with future employment;

- the development of inter-faculty interaction;

- it would be nice if the choice of subjects was not "compulsory" for students. university environment, they expect authenticity in professional choice, teaching and evaluating its results; authenticity of the teacher's professionalism and of personal meanings laid in the educational process. A guarantee of interest in education besides the interest in a subject is the professionalism and personal qualities of a teacher and the form of material presentation. A student is ready to study, to become interested, to enter the dialog, to get a real grade. A student wants to think, reflect and rely on adequate criticism of their answers.

It is also worth mentioning that students expect the university to provide them with versatile development (creative and sports), affordable accommodation (dormitory), high scholarships and, of course, the participation in the further employment of its graduates.

The university should provide the conditions for the meeting of two personalities: the mature and experienced personality of a teacher and still immature student's personality, creating an environment for synergetic interaction between both sides. This communication is an integral part in forming Soft skills. Perreault defines soft skills as personal qualities, attributes or a level of a person's commitment that distinguishes a person from the others who may have similar skills or experience [2].

James and James agreed that soft skills are a new way of description a set of abilities or talents, which a person can bring to the workplace. Soft skills characterize certain career attributes that people may have, for example, teamwork, communication skills, leadership skills, customer service and problems solving skills [3].

Sutton in his study concluded that soft skills are so important that employers put them in the first place when choosing job seekers for positions in all industries [4].

Glenn pointed out that employees who have soft skills contribute to the organization high productivity in order to maintain a competitive advantage [5].

Soft skills are recognized as "skills, abilities and features which relate to a personality and behavior and not to formal or technical knowledge" [6]. In particular, it was suggested that soft skills should include interaction and motivation, including oral communication, teamwork, commitment and reliability. The environment of a classical university should consist of fundamentality, openness, variability and redundancy, creating an environment of open choice for all subjects of sociocultural educational space.

Currently the research in Kuban State University is in process. The aim of it is to create a model of identifying the potential of the socio-cultural educational environment of a classical university for soft skills development among students.

The authors distinguish two types of sociocultural environments ("Fig. 3"). 


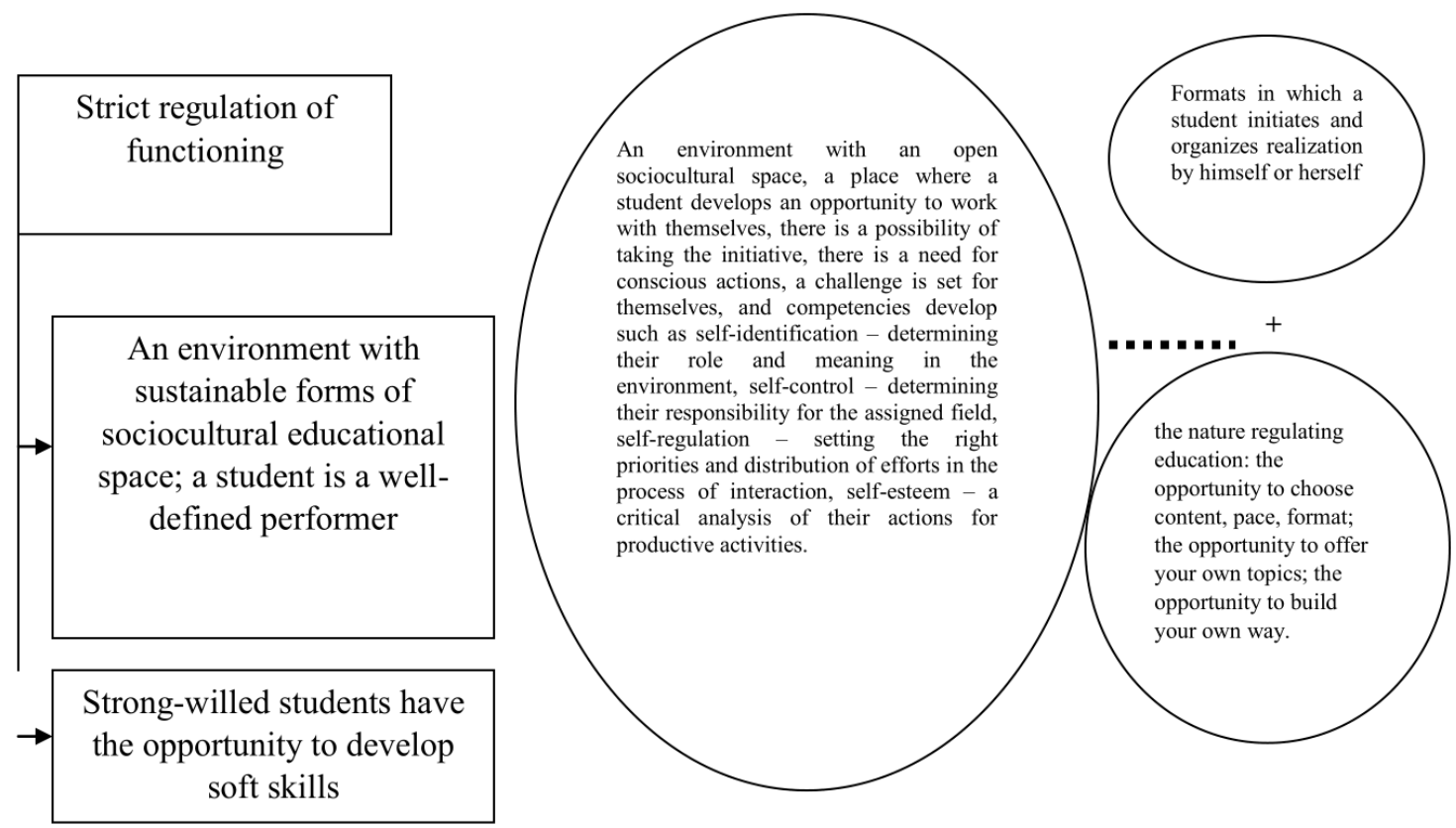

Fig. 3. The types of sociocultural environments.

In the first environment "Tight regulation of functioning" i.e. an environment with fixed forms of sociocultural educational space, a student is a well-defined performer; such competencies as adaptability and flexibility develop.

"Flexible regulation of functioning" is an environment with an open sociocultural educational space where a student develops the ability to work with himself or herself. When it is possible to take an initiative, there is a need for conscious actions, a challenge is put to oneself and such competencies are formed as self-identification - determining their role and meaning in the environment, self-control - determining their responsibility for the assigned field, self-regulation - setting the right priorities and distribution of efforts in the process of interaction, self-esteem - a critical analysis of their actions for productive activities.

Thus, we are talking about the fact that in this very environment the maximum formation of everything connected with the "self" happens and in our case with the soft skills formation.

In the first environment only students with the most manifested volitional qualities can develop. Gradually adding new forms, themes, means of realization, "sample" events to the environment, it acquires a variability of meanings and contents, possibly changing the system of environment functioning. Hypothesis is a direct correlation between the presence of such models as opportunities and changes in the environment of students and the percentage of students showing and developing soft skills.

Thus, if we consider the sociocultural educational environment of the university as a system, we can distinguish two components: regional and local. The regional level includes educational policy, culture, education system, lifestyle in accordance with national and social norms, values, customs and traditions, mass media etc.
The local level includes the educational institution itself, the immediate environment and family. It is the interaction with this environment that can have the most powerful influence on the formation of the student's picture of the world. Such local environments have a special impact, because in these conditions a personally significant communication and life activity of a young person take place.

\section{CONCLUSION}

The problem of studying soft skills is very relevant nowadays, both in Russia and abroad. Due to their characteristics, the given competencies are difficult to track, measure and form. But it is precisely the modern conditions of society which consider their presence in a person as an important factor, the new rhythm of life creates the conditions for their development, manifestation, and, most importantly, application. Moreover, it is up to each person whether to use, develop, form and apply these competencies; it depends on the life goals and objectives set. However, one thing is obvious that soft skills are the competencies of the new time.

\section{REFERENCES}

[1] G. N. Prozumentova. Formation of mechanisms of open educational space. Tomsk. Tomsk: Publishing house of TSU, 2000.

[2] H. Perreault, (2004, October). Business educators can take a leadership role in character education. Business Education Forum, 59(1), 23-24.

[3] R. F. James, M. L James (2004, December). Teaching career and technical skills in a "mini" business world. Business Education Forum, 59(2), 39-41.

[4] Sutton, N. (2002, August 9). Why can't we all just get along? Computing Canada (28)16, 20. 
[5] Glenn, J. L. (2008, April). The "new" customer service model: Customer advocate, company ambassador. Business Education Forum, 62(4), 7-13.

[6] Moss, P., \& Tilly, C. (1996). "Soft" skills and race: An investigation o f black men's employment problems. Work and Occupations, 23(3), p. 256 